\title{
Hydropower Production Profiles: Impacts on Capacity Structure, Emissions, and Windfall Profits
}

\author{
Maria Kopsakangas-Savolainen ${ }^{1,2,3}$ and Rauli Svento ${ }^{3}$ \\ ${ }^{1}$ Finnish Environment Institute, University of Oulu, P.O. Box 413, 90014 Oulu, Finland \\ ${ }^{2}$ Thule Institute, University of Oulu, P.O. Box 7300, 90014 Oulu, Finland \\ ${ }^{3}$ Department of Economics and Martti Ahtisaari Institute of Global Business and Economics, P.O. Box 4600, \\ University of Oulu, 90014 Oulu, Finland
}

Correspondence should be addressed to Maria Kopsakangas-Savolainen; maria.kopsakangas@oulu.fi

Received 14 October 2013; Accepted 16 March 2014; Published 14 April 2014

Academic Editor: Fushuan Wen

Copyright (C) 2014 M. Kopsakangas-Savolainen and R. Svento. This is an open access article distributed under the Creative Commons Attribution License, which permits unrestricted use, distribution, and reproduction in any medium, provided the original work is properly cited.

\begin{abstract}
Production structure in markets with a significant role of hydropower is sensitive to the production profile of hydropower. In this paper we utilize a long-run oriented real-time price based simulation model to analyze through scenarios the impact of different hydropower production profiles on the total annual energy consumed, prices, and capacity structure. We also show the relation between different hydropower production profiles and emissions, costs, and windfall profits. There seems to be no superior scenario under which all socially desirable goals are achieved as there is a clear tradeoff between allowing high windfall profits with highest cost efficiency and achieving the target for lower emissions.
\end{abstract}

\section{Introduction}

The role of energy as a driver of social and economic development is becoming more evident day by day. The negative externalities related to energy production and consumption govern political debates and decision making. The price of energy combined with low price elasticity raises the share of energy expenditures in household's and firm's budgets. These developments naturally emphasize the importance of properly functioning energy markets.

The significance of hydropower production in hydro dominated regions is recognized by many authors (see, e.g., [1-5]). They point out that even a relatively small firm may have a significant impact on market outcome if demand is inelastic and capacity withdrawn from production has low variable costs which cannot be easily replaced by a production with similar variable costs. Hydropower production is very flexible in allocating water from reservoirs (including the impacts of weather conditions and varying yearly precipitation to the model are very demanding tasks excluded from this analysis; however, in the future our aim is to extend the model to include these aspects as well) and the variable costs of production are very low.

The aggregate role of different hydropower production profiles has, however, to our knowledge, not been analyzed. The share of hydropower in Nordic power market is significant but there is also a mixture of other production technologies (nuclear, thermal power, wind power, gas turbines, etc.) present. These facts together offer a very good basis for this kind of analysis. Our study contributes to the existing literature by combining an economic value approach model [6-8] to different hydropower profiles in the Nordic power market.

It has clearly been noticed in the literature that the potential for strategic behavior (market power) is susceptible in markets with a significant role of hydropower stations (see, e.g., [4]). Most literature has approached the issue of market power by using multiperiod (or intertemporal) hydrothermal scheduling problem (see, e.g., [9-12]). Førsund [13] gives a comprehensive survey of this literature. Bushnell [9] shows that it is optimal for strategically behaving hydropower firms to allocate water away from periods with inelastic residual demand into periods where their residual 
demand is relatively more elastic. In practice this means that hydropower generators move supply from hours with high demand to those with lower demand. A reduction in output during peak hours can result in significant price increases. Crampes and Moreaux [10] show that even in the first-best allocation the thermal output is determined by intertemporal considerations.

Kauppi and Liski [14] differ from these models in the sense that they have a long run perspective. They estimate the market structure which best explains the real behavior of Nordic power market in years 2000-2005. They find that a market structure where $30 \%$ of hydropower storage capacity is strategically used fits best the historical market data. This literature on possible strategic behavior of hydropower generators clearly points to the possibilities of existing market failures.

Regardless of clear merits of these kinds of models it is not possible to analyze the whole capacity structure through them. This is because these models typically include only two types of technologies, hydro and thermal, and consequently they are more suitable for analyzing the use of existing capacities, abstracting from long-run questions related to investments and structure of the whole energy system. We contribute this deficiency such that the model which we use in this paper offers a possibility to analyze the whole capacity structure of the power market.

There is also a growing literature analyzing the role of hydropower in order to buffer intermittent renewable generation (see, e.g., [15]). Many studies evaluate the performance of combined wind and hydro systems and conclude that a significant increase in the productivity of intermittent generation may be achieved with a combined use with hydroelectric power [16-19]. Chang et al. [15] use holistic grid resource integration and deployment model (HiGRID) in order to observe the hourly impact to the generation system when increasing renewable penetration. They show that by adjusting hydro production with wind the penetration of wind increases significantly. Kaldellis and Kavadias [16] show that combined wind-hydro energy production stations have clear impact on renewable energy sources utilization in Aegean Sea islands. Kaldellis et al. [17] conclude through simulated sensitivity analysis that the contribution of renewable energy to energy system may be increased by almost $15 \%$ when incorporated with pumped-hydro storage systems in Greek remote islands. Even though these models typically offer the possibility to analyze whole capacity structure these models do not include the demand function of electricity which is sensitive to hourly market prices and thus the effect of the wholesale electricity price to the capacity structure is not possible to analyze through these kinds of models.

Combining an economic value approach model to different hydropower profiles enables the analysis of the impact of different hydropower profiles to other capacities but also to economic issues such as cost efficiency and industry profits and also emissions. In order to analyze different hydropower production scenarios we utilize a long-run oriented real-time price (RTP) based model (see, e.g., [6-8]). We have chosen this kind of approach for two reasons. First, real-time price based contracts are becoming increasingly common and it is important to model the demand side in such a way that it reflects this fact. Secondly, this kind of approach allows us to model the technology mixture of supply side more realistically than, for example, intertemporal optimization models which typically use only two kinds of technologies.

The structure of the paper is as follows. In Section 2 we describe and discuss the main fundamentals and features of the Nordic power market. Section 3 provides a formal description of the simulation model and in Section 4 we present the results. Section 5 concludes the paper.

\section{Nordic Power Market}

The Nordic power market was the first international power market and it consists of four Nordic countries: Sweden, Finland, Norway, and Denmark (Estonia joined the common Nordic power market in 2010 and Lithuania in 2012; because we use data from earlier dates we exclude these from this study). These countries run a common power exchange, the Nord Pool, where market participants can buy and sell electricity. The common power market was mainly motivated by efficiency reasons. The mixture of production technologies in the Nordic power market is quite large and it has been argued that it would improve the efficiency of production if market participants could trade between countries. The main part of the production in Finland and Denmark is based on thermal generation, whereas Norway is a very hydrointensive country (99\% of the Norwegian electricity production is based on hydropower). In Sweden the electricity production is mainly based on hydropower and nuclear power.

In the Nordic power market the wholesale trade of electricity is organized through Nord Pool power exchange. It is owned by national transmission system operators. The power exchange operates in such a way that market participants make their quantity-price bids one day in advance to the hourly market. This market is called Elspot, where demand and supply schedules are aggregated. The resulting market clearing price for each hour is called the system price. Even though Nord Pool is a voluntary market more than $70 \%$ of the total consumption of electricity was traded through it in 2009.

The transmission grid of the Nordic power market is operated by the national transmission operators. If the transmission across borders is not congested there is only one system price. If the transmission is congested then the regions split into price areas. Nord Pool Spot manages the capacity on the interconnectors between the Nordic countries and the cables that connect the bidding areas. A privileged place on a bottleneck could be abused by a market participant and it is therefore essential that the capacity is given to a neutral party (see, e.g., Nord Pool webpages for the discussion of bottlenecks). In our simulations we assume that the Nordic power market always forms only one price area.

Total net electricity production in the Nordic market was 367 TWh in 2009 (see Eurelectric [20]). Of the produced electricity 72,6 TWh was based on nuclear power, 205,1 TWh was based on hydropower, 61,7 TWh was based on using conventional thermal power plants, and 27,6 TWh was based on 


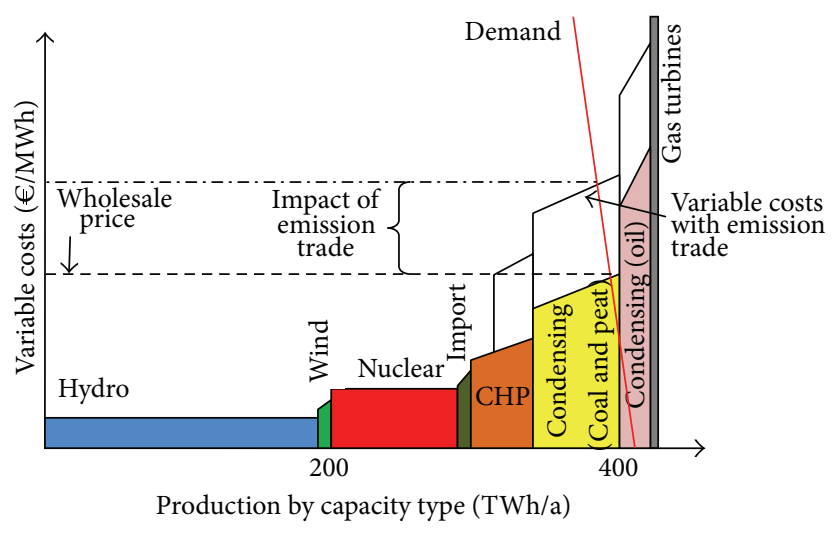

FIGURE 1: Production structure of Nordic power market.

other renewables (nuclear power production was at a lower than average yearly level in 2009). The amount produced by hydropower can change quite much from year to year depending on precipitation. When the precipitation of the year is low, power is exported from Finland and Denmark to hydro dominated regions, and in the high precipitation years the opposite is true. There are five nuclear power plants currently operating in Nordic countries. Three of them (10 reactors) are located in Sweden, whereas two of them (4 reactors) are located in Finland. There is also one more $1600 \mathrm{MW}$ reactor under construction and permission to construct two more reactors in the near future in Finland. Characteristic to the Nordic energy market is that a large part of the conventional thermal power is produced by combined heat and power (CHP) plants. The peak technology includes oil fired condensing power plants as well as gas turbines.

From Figure 1 one can observe the production structure of the Nordic power market on an annual level. The figure can be also used to describe the basic idea of the formation of the wholesale price (then the horizontal axis should be rescaled to fit hourly production capacity). Wholesale price of an hour is based on the intersection of system marginal costs (including the impact of emission price) and a demand for that hour. From Figure 1 the important role of hydropower can be observed. The amount of hydro production on a specific hour shifts the whole system marginal curve inwards or outwards and thus has significant impact on the wholesale price of that hour.

In our simulations as shown in Figure 1 we divide our technologies into four representative technology groups based on the main characteristics of the Nordic power market. According to our view this somewhat less diversified production structure is sufficient for the purpose of this study and it enables us to concentrate on the main purpose of the study, namely, to model more detailed hydropower production profiles and analyze the impact of the changes in these profiles to other variables (the role of other renewables (other than hydro) is not specifically studied in this paper; however, it should be recognized that as the share of other renewables increases their importance to the whole production system also increases (see, e.g., Kopsakangas-Savolainen and Svento
[21] for the analysis of intermittent power generation in the Nordic power market)).

The aggregate demand for electricity in Nordic countries has been quite stable from year to year and the increase has been mainly due to economic growth. Some yearly variations happen along with variation in temperature. Price elasticity of demand has typically been very low because the price that final customers face is typically fixed for some period of time and prices do not follow the pattern of wholesale prices in the short run. Economists have argued that the absence of real time pricing is one of the most obvious shortcomings of the functioning of the electricity markets from an efficiency point of view. This is mainly because if demand does not respond to prices, we need too much reserve power capacity to meet the demand also in highest peak hours (and this is of course very costly).

\section{The Model}

3.1. Theoretical Background. Deregulation of electricity generation is based on the idea that competition increases efficiency in liberalized electricity markets. But there is a fundamental question related to this idea in electricity markets. The efficiency gains from competition are based on the fact that the price mechanism allocates decentralized decisions into an efficient outcome for the whole market. The realization of this competitive equilibrium necessitates that the price mechanism operates without any rigidities. As economists have long pointed out, this assumption is not yet true in electricity markets. In these markets the wholesale price in generation is determined hour by hour as a price that equates supply and demand. The retail price, however, is in most cases based on medium or long term contracts with fixed rates which do not react to hourly wholesale prices.

The simulation model that we construct reflects this and other features of the Nordic electricity market as closely as possible. This model, however, has a firm theoretical background on which it is based and which is described in detail in Borenstein and Holland [7]. Here we will give the basic theoretical assumptions and results. The model is based on the assumption of competition both in generation and in retail. In generation, profit maximizing generators choose their hourly supply based on marginal cost of generation (Borenstein and Holland assume a continuous supply curve but the results generate into L-shaped curves as well). The demand curve is a constant elasticity curve so that the utility maximizing consumers do not end up in corner solutions. A fixed share of customers has real-time price based agreements and the rest have a flat-rate agreement. The price elasticity is constant and exogenous. Competition in the retail sector forces the retailers into Bertrand competition so that the retail prices are set so that the retailers have zero profits.

Based on these behavioral assumptions Borenstein and Holland show [7] that the short run competitive equilibrium has, for a given capacity and given share of customers in realtime pricing, real-time retail prices that are equal to wholesale (real-time) prices and the flat-rate price equals the demandweighted average wholesale price. The wholesale prices are 


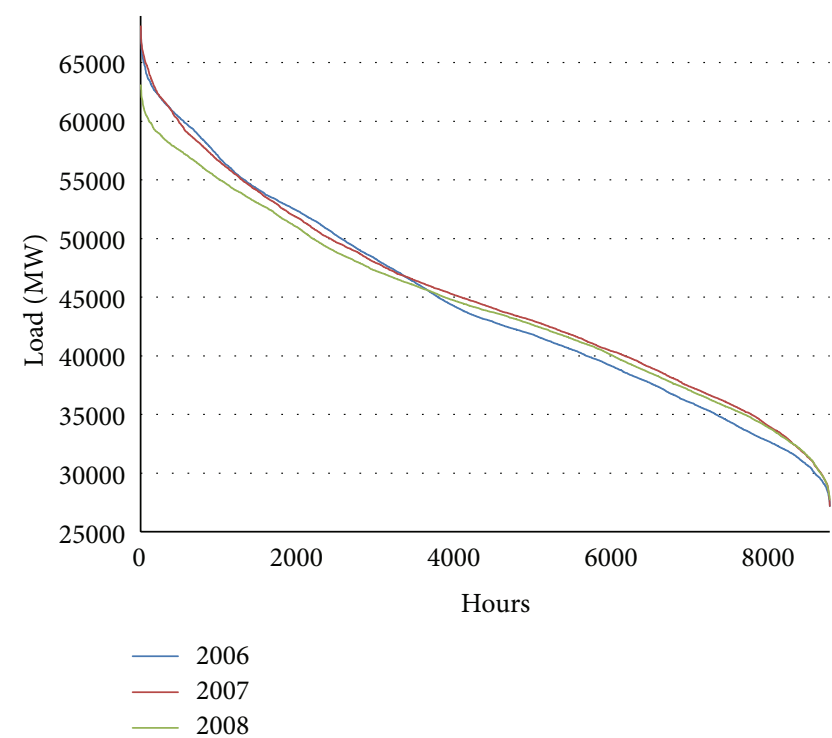

FigURE 2: Load duration curves in Nordic power markets from 2006 to 2008 .

determined so that they are equal to marginal generation costs when using fixed capacities.

Generation capacity will enter the wholesale market as long as short-run profits are positive. Investments then drive the long-run generation profits to zero and the long-run competitive equilibrium wholesale prices are characterized by the conditions of the short run equilibrium plus the additional zero profit condition where investment costs are taken into consideration. In the case when some technologies are capacity constrained, however, these technologies may take positive profits. The conditions for long-run equilibrium wholesale prices still hold also in this case.

3.2. Structure of the Simulation Model. The simulation model is based on the model developed by Borenstein and Holland [7], Borenstein [6], and Kopsakangas-Savolainen and Svento [8]. Our application here differs from these earlier specifications in that we assume hydropower producers may allocate available water reserves strategically.

Next we present the general logic behind the simulation model. We assume a constant elasticity demand function. Since we do not estimate this demand function we have to calibrate it to correspond to the realized demand profiles. We have used the information on the load duration curve to do this. Our hourly load duration curve is based on inspecting the hourly consumption data from Nord Pool Spot from 2006 to 2008. The hourly demand varies from $27173 \mathrm{MW}$ (lowest hour in 2006) to $68111 \mathrm{MW}$ (highest hour in 2007). As can be seen from Figure 2 the shapes of the load duration curves are rather similar among different years and also for the previous and more recent years. Also the aggregate demand for electricity in Nordic countries has been quite stable from year to year. Some yearly variations happen along with variation in temperature. We have chosen to use 2008 load duration curve in our simulations because of two reasons. First, the difference between highest and lowest demand hours is smallest in year 2008 and so the simulation results give a lower bound for the effects of RTP. If we use a steeper load duration curve it would strengthen the following RTP results. Secondly, the long run expectation is that the load duration curve will be rather flat due to the utilization of intelligent technology. Through smart technology it is possible to manage both the demand and supply sides of the markets more effectively (see Kopsakangas-Savolainen and Svento [22] for modeling the electricity market as a twosided market). The main role of the load duration curve is to give an anchor point to the model demand function and consequently, as long as the structure and level of the demand do not change significantly, the analysis using year 2008 load duration curve can be generalized to concern more recent years as well.

In practice the specification of the demand function has been done by calculating a scaling factor called "anchor point" $A_{h}$ for each hour of the year. In order to specify the anchor point we need to assume an hourly price. We have used such a constant hourly price that if charged to all customers as a flat rate it would allow producers just to break even. The anchor point is as follows: $A_{h}=D_{h} / p_{c}^{\varepsilon}$, where $D$ is demand, $h$ is hour, $p_{c}$ is the constant price, and $\varepsilon$ is the price elasticity for homogenous customers. It is more important that we have accurate information of the shape of the hourly demand distribution than very specific information on the constant price. These anchor points are used to scale the demands to the load duration curve. Now let $\alpha, 0<\alpha \leq 1$, be the share of customers on real-time pricing, $p_{r}$ the retail price of electricity for the RTP customers, and $p_{f}$ the flat rate price for non-RTP customers. The constant elasticity demand for electricity for hour $h$ can then be written as follows:

$$
D_{h}\left(p_{r}, p_{f}\right)=\left[\alpha p_{r}^{\varepsilon}+(1-\alpha) p_{f}^{\varepsilon}\right] A_{h}, \quad h=1, \ldots, 8760 .
$$

The simulation results related to the effect of RTP are based on varying $\alpha$ and $\varepsilon$ exogenously. In this paper we assume $-0,025$ for the price elasticity value and 0,33 for the share of RTP customers (several studies support the view of inelastic electricity demand in Nordic countries (see, e.g., Johnsen [23] (2001), Damsgaard [24] (2003), and Bye and Hansen [25] (2008)); there are no statistics available for the recent share of the customers under RTP contracts and we base our assumption of the value of $\alpha$ on discussions with industry representatives).

We assume a competitive market structure in generation and in retail. We also assume that both retailers and generators will maximize profits and their profit functions can be written as follows:

$$
\begin{gathered}
\pi_{R}=\sum_{h=1}^{8760}\left[\left(p_{f}-w_{h}\right)(1-\alpha) D_{h}\left(p_{f}\right)\right. \\
\left.+\left(p_{r}-w_{h}\right) \alpha D_{h}\left(p_{r}\right)\right], \\
\pi_{G}=\sum_{h=1}^{8760}\left(w_{h} D_{h}-c D_{h}\right)-r K,
\end{gathered}
$$




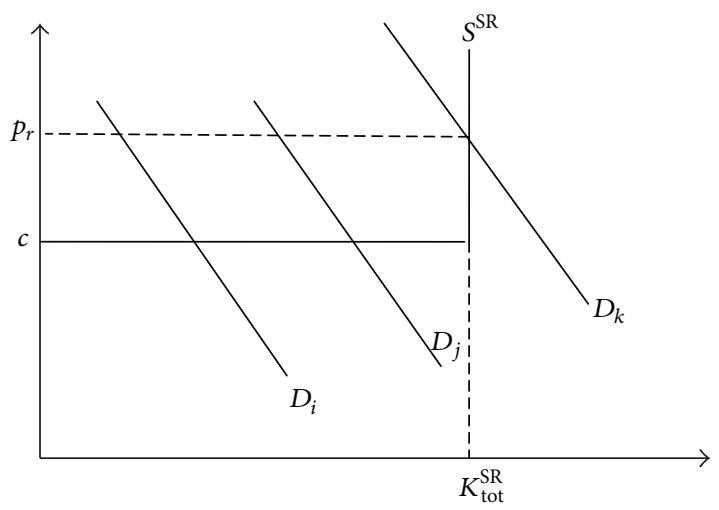

FIGURE 3: The energy system with only one technology.

where $R$ is retail sector, $G$ is generation sector, $w$ is wholesale price, $c$ is marginal generation costs, and $r K$ is annual capital costs. In the model the retailers can be seen as energy brokers with only very small operating costs (ignored in this analysis) (note that the distribution sector is not included in the analysis).

From (1), (2), and (3) we can solve for short-run and long-run equilibrium of the generation and consumption systems. The logic of the simulation system is that the whole generation system is constructed MW by MW under the assumed economic principles (i.e., generators maximize profits according to (3)). After the construction of the whole generation system we turn to the retail sector and adjust the flat rate as long as the profits (see (2)) for the retail sector are equal to zero. Then, we turn again to the generator sector and rebuild the whole system MW by MW with this new flat rate. These two rounds are repeated until we reach the long-run equilibrium of the whole system.

3.2.1. Equilibrium with One Technology. To describe the simulation model and the solution procedure in a simple way, assume first that only one capacity type without any scale effects is constructed and used. The short run supply curve with an assumed short-run capacity $K_{\text {tot }}^{\mathrm{SR}}$ is thus an inverted L-shaped curve as depicted in Figure 3.

The short-run profits by hour are maximized by maximizing $\pi_{G}^{\mathrm{SR}}=w_{h} D_{h}-c D_{h}$ with respect to given demand so that we have the known result: $w_{h}=c$. But this is true only when demand is not greater than the capacity limit, that is, demands $D_{i}$ and $D_{j}$ in Figure 3. For those hours that demand exceeds the short-run capacity limit the real-time price must adjust for the market to clear. In equilibrium it has to be that demand is equal to supply; that is,

$$
D_{k}=\left[\alpha p_{r}^{\varepsilon}+(1-\alpha) p_{f}\right] A_{h}=K_{\text {tot }}^{\mathrm{SR}} .
$$

From there we can solve for the price $p_{r}$ :

$$
p_{r}=\left[\frac{K_{\mathrm{tot}}^{\mathrm{SR}}-(1-\alpha) p_{f} A_{h}}{\alpha A_{h}}\right]^{-\varepsilon} .
$$

So the wholesale pricing logic is as follows:

$$
\begin{array}{cc}
w_{h}=c & \text { when } D_{h} \leq K_{\mathrm{tot}}^{\mathrm{SR}}, \\
w_{h}=p_{r} & \text { when } D_{h}>K_{\mathrm{tot}}^{\mathrm{SR}} .
\end{array}
$$

Once we know the demand and wholesale price for each hour we can calculate profits for the generators. Because of competition we assume that capacity is built to the point where profits are equal to zero.

Next we solve for the flat rate. Competition forces the retail sector to zero profits also in the short run. Abstracting from transmission and retail costs the real-time retail price must always be equal to the wholesale price. Should this not be the case there would be possibilities for undercutting the market price and this will go on as long as the retail price exceeds the wholesale price. So the zero profit condition for the retail sector reduces to

$$
(1-\alpha) \sum_{h=1}^{H}\left(p_{f}-w_{h}\right) D_{h}\left(p_{f}\right)=0
$$

from which we can solve for $p_{f}$ :

$$
p_{f}=\frac{\sum_{h}^{H} w_{h} D_{h}\left(p_{f}\right)}{\sum_{h}^{H} D_{h}\left(p_{f}\right)} ;
$$

that is, the zero profit short-run flat rate is a weighted average of the real-time wholesale price with weights being the relative quantities demanded by customers facing a flat retail price.

In the long run, capacity is built to the point where both generators and retailers receive zero profits. As shown in Borenstein-Holland (2005) and Borenstein (2005) this kind of mechanism leads to a unique long-run equilibrium for the total generation capacity, $K_{\text {tot }}^{\mathrm{LR}}$.

3.2.2. Equilibrium with a Technology Mix and Description of the Iteration Procedure. We can use the same kind of procedure as explained above to solve for the technology mix. Now the total technology build consists of different types of technologies with different capital and variable costs. Because of competition we assume that capacity, for those technologies which are not capacity constrained, (peaker and midmerit technologies in our case) is built to the point where profits are equal to zero. Those technologies which are capacity constrained (hydropower and nuclear power in our simulations) are built either to the point where their profits are zero or to the limit of the capacity constraint. In practice we first solve for short run total capacity $K_{\text {tot }}^{\text {SR }}$ by using peaker capacity only (as described above). Then, we start to replace peaker capacity with midmerit capacity. We construct the midmerit capacity to the point where the short-run profits for midmerit capacity go to zero. Lastly, we construct the capacity constrained technologies (nuclear and hydro) either to the point where their short-run profits are zero or to the point where they reach the limit of their capacity.

After the short run technology mix for generation is solved we turn to the retail market and solve for the short run 


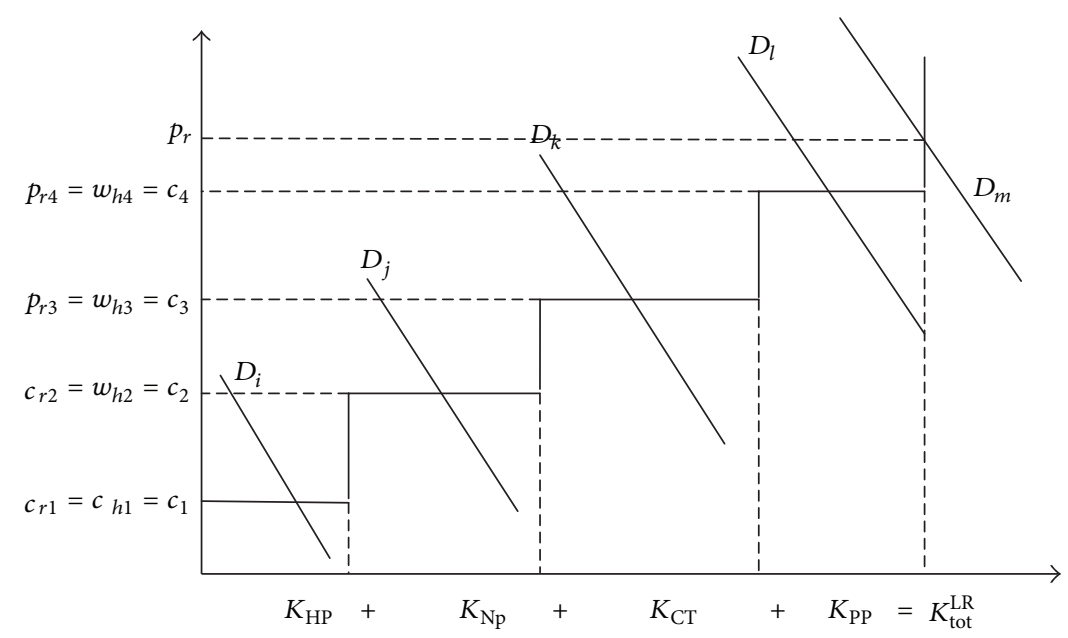

$K_{\mathrm{HP}}$ is hydropower capacity

$K_{\mathrm{Np}}$ is nuclear power capacity

$K_{\mathrm{CT}}$ is conventional thermal power capacity

$K_{\mathrm{PP}}$ is peak power capacity

$K_{\text {tot }}^{\mathrm{LR}}$ is total power capacity

FIgURE 4: The long-run structure of the energy system.

equilibrium for the retail market. Short run equilibrium for the retail market is reached when the retail sector produces zero profits (see (7)). From the zero profit condition we can solve for the new flat rate. With this new flat rate we start to construct again the whole generation technology mix. These two rounds are repeated until the equilibrium conditions for both sectors are simultaneously fulfilled (see also Kopsakangas-Savolainen and Svento [8] and Borenstein and Holland [7] where long-run equilibrium is reached through a similar procedure). The long-run energy system equilibrium is described in Figure 4.

In order to find the long-run equilibrium with a technology mix the following iteration procedure is used.

(a) Begin with an initial guess for the peaker technology capacity. We begin with peaker technology because if it is used at all, it will be used in the highest demand hour. Expand (the initial guess for the peaker capacity has to be always such that the resulting profits are positive) the quantity of peaker capacity, combine this short run supply function with the hourly demand, and calculate short-run profits of the peak power generator. Continue the expansion of the capacity until expansion by one more unit causes profits to go negative for peak power generators. The resulting amount of capacity will typically be the short run equilibrium of total amount of all capacities $\left(K_{\text {tot }}^{\text {SR }}\right)($ see Figure 3).

(b) Next, start substituting peaker capacity with midmerit capacity. The midmerit capacity will be lower on the supply function than the peaker capacity because of lower variable costs and thus it will be used in all hours before any of the peaker capacity. Follow the same procedure as with the peaker capacity. We refer to the total amount of midmerit capacity that still results in positive profits by $K_{\text {mid }}$.

(c) Next begin substituting midmerit capacity by the baseload capacity (nuclear in our case). Follow the same procedure as in stages (a) and (b) above. Note, however, that we have assumed that the baseload capacity is constrained. Refer to the amount of baseload capacity by $K_{b}$.

(d) Next take the capacity of hydropower generation into account at each hour of the year based on the assumed hydropower production strategy (these strategies are described in Section 4.1). Note that we allow hydropower producers to make positive profits through market power abuse. Refer to the amount of hydropower capacity by $K_{\mathrm{HP}}$.

(e) Now one has determined the capacities of all types of technologies. One can determine short-run amounts of capacities using the following recursive logic:

(i) hydropower $=K_{\mathrm{HP}}=K_{\mathrm{HP}}$;

(ii) nuclear power $=K_{\mathrm{NP}}=K_{b}-K_{\mathrm{HP}}$;

(iii) conventional thermal power $=K_{\mathrm{CT}}=K_{\text {mid }}-$ $K_{\mathrm{NP}}-K_{\mathrm{HP}}$;

(iv) peaker power $=K_{\mathrm{PP}}=K_{\text {tot }}^{\mathrm{LR}}-K_{\mathrm{CT}}-K_{\mathrm{NP}}-K_{\mathrm{HP}}$.

(f) The final step of this procedure is to satisfy also the retailer breakeven condition. This happens by calculating the profits that the retailers earn from flat rate customers in this specific wholesale-producers equilibrium (note that profits for the retailer from RTP customers are always equal to zero). If the retailer 
TABLE 1: Capacity and generation costs.

\begin{tabular}{lccc}
\hline Generation type & Annual capital costs $€ / \mathrm{MW}$ & $\begin{array}{c}\text { Variable costs without emission } \\
\text { trade } € / \mathrm{MWh}\end{array}$ & $\begin{array}{c}\text { Variable costs with emission } \\
\text { trade } € / \mathrm{MWh}\end{array}$ \\
\hline Hydropower & 67336 & 4 & 4 \\
Nuclear power (baseload) & 118697 & 15 & 15 \\
Conventional thermal power (midmerit) & 74657 & 32 & 52 \\
Peaker power & 40200 & 45 & 60 \\
\hline
\end{tabular}

profits are negative, one adjusts the flat rate price up, and if profits are positive one adjusts the flat rate price down.

This procedure (steps from (a) to (f)) is continued until we reach an equilibrium where retail markets also yield zero profits. Once the flat rate equilibrium has been reached we have also solved the long-run unique competitive equilibrium energy system size and structure for a given set of available technologies, technology constraints, and share of customers on RTP and on flat rate.

3.3. Data for Simulations. In addition to the load duration curve data we also need information on costs of the different production technologies. The production specific cost data is presented in Table 1 . The variable costs of midmerit and peaker units are determined with and without emission trade. Variable costs include fuel costs, operation and maintenance costs, and the impact of the emission price. Assumed emission price is $23 € / \mathrm{tCO}_{2}$, which is close to the average emission price during the year 2008 (since we use the 2008 load duration curve it is consistent to use also the emission price from the same year; we have done also sensitivity analysis with different emission prices; lower emission price reduces windfall profits and makes midmerit technology relatively more competitive to peaker technology (this causes also higher emissions) (the opposite is true for the increase in emission price)). The impact of emission price to the variable costs is calculated by assuming that midmerit technology uses peat and coal as fuel, whereas peaker technology uses gas and oil. The $\mathrm{CO}_{2}$ multiplier is higher for midmerit technology than for the peaker technology and consequently the increase in variable costs as a result of emission trade is relatively bigger for midmerit technology than for peaker technology. In emission calculations and in the calculations of the impact of emission price to the variable costs we have used the following fuel based $\mathrm{CO}_{2}$ multipliers: $382 \mathrm{kgCO}_{2} / \mathrm{MWh}$ for peat, $341 \mathrm{kgCO} / \mathrm{MWh}$ for coal, and $279 \mathrm{kgCO}_{2} / \mathrm{MWh}$ for oil. These values refer to primary fossil fuel emission contents and they are transformed to correspond to electricity production per MWh by taking the efficiency factor of underlying production technology into account (production technology based efficiency factors are as follows: $58 \%$ for gas, $42 \%$ for coal and oil, and $40 \%$ for peat) (for detailed calculations of the impact of emission price to the variable costs of different technologies reader is referred to see Tarjanne and Kivistö [26]). Of course the actual mixture of production technologies is somewhat more diversified but for the purpose of this study a somewhat less diversified production structure is sufficient.
As discussed above, hydropower is a very important technology in the Nordic power market. Hydropower differs from other technologies because of very low variable costs and its dependence on the precipitation of the year. It cannot be clearly identified as belonging to baseload, midmerit, or peaker capacity. Part of it can be used as baseload capacity but most of it is used as balancing power. The cost of hydropower production depends on the type of the power plant and on other environmental factors. The annual capital cost of each technology in our simulations is calculated by assuming 3\% interest rate and by using standard annuity formula. It is important to use annual capital cost since in the simulation model the demand is determined by the annual hourly load duration curve and consequently we need also costs determined on a yearly basis. For hydropower we assume that investment costs are $2000 €$ per installed $\mathrm{kW}$ and that economic lifetime of that capacity is 75 years. With the interest rate of $3 \%$ and using standard annuity formula we end up with the $67336 €$ capital cost per year. Variable costs include fuel costs, operation and maintenance costs, and the impact of emission permits price to the variable costs. In the case of hydropower, variable costs are basically equal to maintenance costs because fuel costs are equal to zero. In the simulations we are assuming that the average utilization rate of the hydropower capacity is slightly below $50 \%$.

In simulations nuclear power production is assumed to be baseload production. Our cost data for nuclear power is based on the calculations by Tarjanne and Kivistö [26]. According to their calculations the specific investment cost of nuclear power is $2750 € / \mathrm{kW}$. If we assume 40 years economic lifetime we end up with the annual capital costs of $118697 € / \mathrm{MW}$. There is wide variation in the estimates of the investment costs for new nuclear power plants. For example, the investment costs of the power plant under construction in Finland (Olkiluoto 3) with installed capacity of $1600 \mathrm{MW}$ is assumed to vary from 3 to 4,5 billion Euros and the expected economic lifetime is up to 60 years. Another notable issue is that the safety costs of nuclear power plants are difficult to estimate. Recently Bunn and Heinonen [27] pointed out that "major steps are needed to rebuild the confidence that nuclear facilities will be safe from accidents and secure against attacks." When planning a new nuclear power investment also these safety costs should be considered. These of course decrease the profitability of these investments.

The representative midmerit technology in our simulations is assumed to be coal and peat power plants. We have again based our costs on the results of Tarjanne and Kivistö [26]. The costs of the representative midmerit technology are 
partly (about 35\%) based on peat fired conventional thermal production and partly (about 65\%) on coal fired production. Specific investment costs of the midmerit technology are assumed to be about $1300 € / \mathrm{kW}$ which results in annual capital costs of 74657/MW over 25 years of economic lifetime.

The capital and variable costs of peaker capacity vary depending on the technology used. Part of the peaker demand can be satisfied by oil fired condensing power plants, part by older power plants kept as reserve capacity, and the rest by the use of gas turbines. We assume that a representative peaker capacity investment cost is $700 €$ per installed $\mathrm{kW}$ which results in annual capital costs of $40200 € / \mathrm{MW}$. If we assume smaller capital costs and higher variable costs it strengthens the impact of real-time pricing in simulations.

\section{Hydropower Scenarios and Results}

4.1. Specification of Hydropower Scenarios. In the simulations regarding the structure of the whole energy system we assume that capacities of hydropower and nuclear power are constrained on the current levels of $47816 \mathrm{MW}$ and $11636 \mathrm{MW}$, respectively. Further, we assume that total hydropower production is constrained at the level of $191835 \mathrm{GWh}$ (which corresponds to 2008 hydro production). We assume that nuclear power is utilized evenly throughout all 8760 hours, but the hydropower utilization depends on the different hydropower production profile scenarios. In the simulations this means that even though the total capacity of hydropower is constrained at the level of $47816 \mathrm{MW}$ and total hydro production at the level of $191835 \mathrm{GWh}$, the disposable water reserve is utilized differently according to scenario chosen. We report results of 5 different scenarios of hydropower producers here. The first scenario is called baseload scenario and according to it water reserve is divided almost evenly in all 8760 hours. In addition, we report results of two "extreme" scenarios and two "combination" scenarios. The first extreme scenario (scenario 1) allocates hydropower so that the flat rate is minimized. In the second extreme scenario (scenario 4) hydropower is allocated such that hydropower producers' profits are maximized. Combination scenarios (scenarios 2 and 3) are combinations of the scenarios 1 and 4 . Next we describe in detail the procedure for solving each scenario. The summarization of the scenarios is presented in Table 2 and Figure 5.

In the baseline scenario, hydropower for a specific hour is solved as follows. We begin with the low-load demand hours in the load duration curve and move hour by hour to the peak demand hours of the load duration curve. If the total yearly hydropower production would be produced uniformly within the 8760 hours we should produce $21899 \mathrm{MW} /$ hour. Now, however, we must remember that we assume that there will be $11636 \mathrm{MW}$ baseload productions by nuclear power in each hour. This means that in the beginning of the load duration curve there will be few hours when demand is less than the sum of average nuclear power production $11636 \mathrm{MW}$ and average hydropower production $21899 \mathrm{MW}$. In these hours we use hydropower less than $21899 \mathrm{MW}$ which means that we have more hydro reserves in the rest of the
TABLE 2: Summarization of the strategies behind different hydropower scenarios.

\begin{tabular}{|c|c|}
\hline Scenario & Strategy \\
\hline $\begin{array}{l}\text { Baseline } \\
\text { scenario }\end{array}$ & $\begin{array}{l}\text { Water reserve is divided most evenly in all } 8760 \\
\text { hours. }\end{array}$ \\
\hline Scenario 1 & $\begin{array}{l}\text { Allocate hydropower so that the baseload power } \\
\text { will be the driver of market price in as many } \\
\text { hours as possible. }\end{array}$ \\
\hline Scenario 2 & $\begin{array}{l}\text { Allocates more water reserve to the peaker hours } \\
\text { than to the lowload demand hours. }\end{array}$ \\
\hline Scenario 3 & Combination of the strategies of Scenarios 1 and 2. \\
\hline Scenario 4 & $\begin{array}{l}\text { Allocate clearly more hydropower to the peaker } \\
\text { hours than in the other scenarios and at the same } \\
\text { time keep peaker power as the market price diver } \\
\text { in as many hours as possible. }\end{array}$ \\
\hline
\end{tabular}

hours. After the hour when demand is equal to the sum of average nuclear production and hydropower production we divide the water reserve evenly to the rest of the hours. See Figure 5(a) for the description of the usage of hydropower in this scenario.

In scenario 1 our target is to allocate hydropower so that the baseload power will be the driver of market price as long as possible and consequently the flat rate is minimized. This means that we allocate hydropower to the beginning of the load duration curve. We satisfy demand as long as possible just by the use of hydropower and nuclear power with the constraint that the maximum hourly hydropower capacity corresponds to the true maximum hour, $33464 \mathrm{MW}$, used in the Nordic power market in 2008 (this constraint is binding only in scenario 1). Up to this point the market clearing price in our model will be $15 € / \mathrm{MWh}$. After this hour is reached the rest of the yearly water reserve is divided evenly to the rest of the hours. As can be seen from Figure 5(b) this results in a downward jump in the hydropower production when the max hour is reached. Consequently, we suddenly need a lot of peaker or midmerit capacity for the rest of the hours to satisfy demand. The model simulations show that it is not profitable for the midmerit power to come to the market at all because of relatively high capital cost with the use of 3708 hours out of 8760 . Even though the market price in those hours is always higher than variable costs of midmerit technology profits will remain negative. This means that the rest of the demand in higher load hours will be satisfied by the use of peaker technology. The amount of total capacity required in this scenario is consequently rather high.

The hydropower production profile in scenario 4 is set such that profits for hydropower producers are maximised. This happens when water reserve is allocated such that the peaker power is the market clearing technology in as many hours as possible. Water is now allocated heavily to the peaker hours in order to produce more in those hours when the wholesale price is at its highest level. See Figure 5(e) for the description of this scenario.

The next hydropower scenario (scenario 2) is a combination of extreme scenarios (scenarios 1 and 4 ) with $75 \%$ of the characteristics of scenario 4 and $25 \%$ of characteristics 


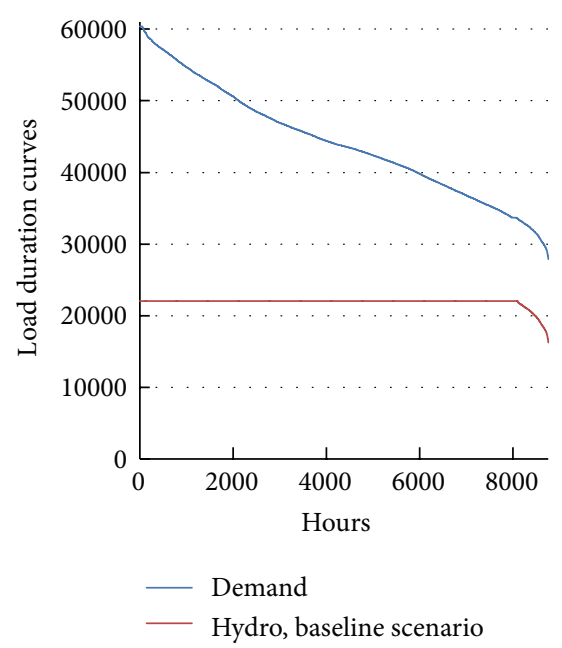

(a) Baseline scenario

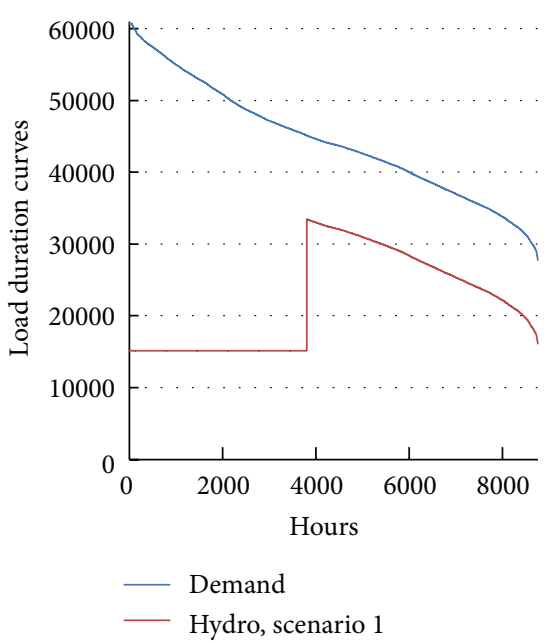

(b) Scenario 1

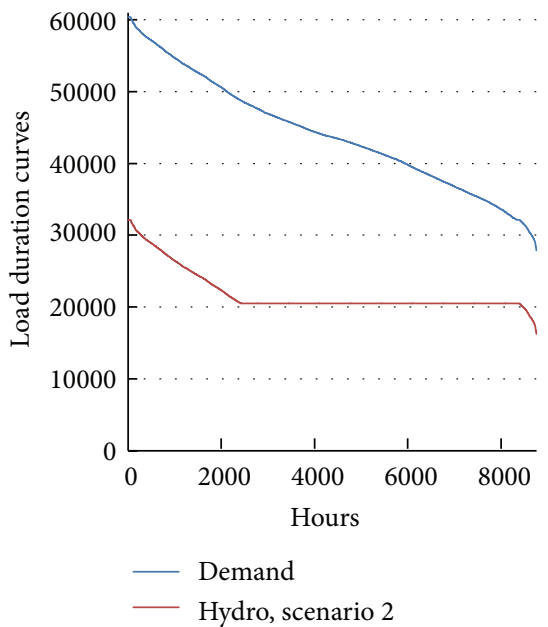

(c) Scenario 2

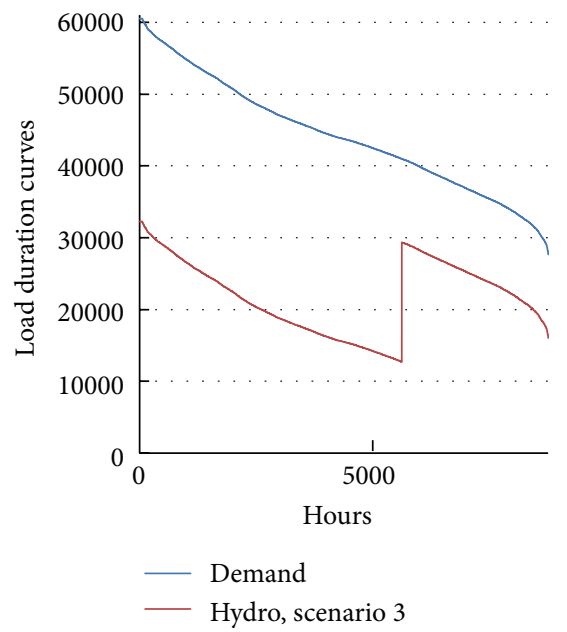

(d) Scenario 3

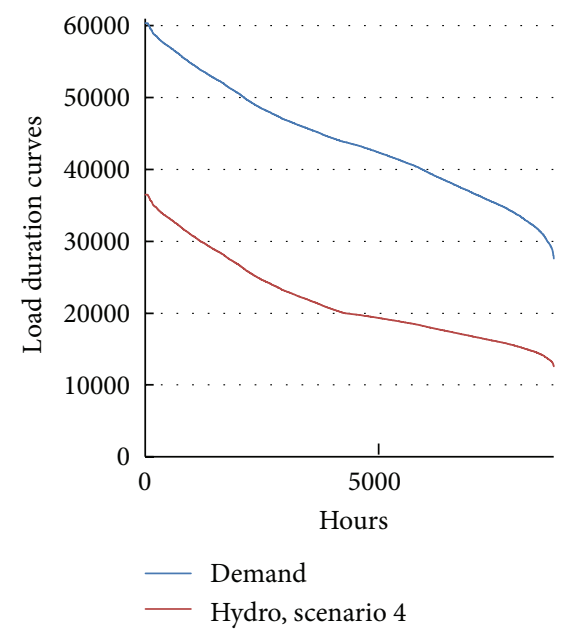

(e) Scenario 4

Figure 5: Hydropower scenarios.

of scenario 1 . This means that in scenario 2 more water is allocated to the peaker hours than to the beginning of the load duration curve hours. We start as in the earlier scenarios and satisfy demand just by using hydro and nuclear in the low-load hours of the load duration curve. Now, however, a bigger share of hydropower is used in those hours when the wholesale price $w_{h}$ is at the peaker capacity determined level; that is, $w_{h} \geq 60 € / \mathrm{MWh}$. In the middle of the load duration curve there is a period when the hydropower production is constant. The target of this scenario is to show the impact of allocating a bigger share of hydropower to the peaker hour production than in the beginning of load duration curve. See Figure 5(c) for the shape of the hydropower production in this scenario.

Scenario 3 is another combination scenario. Now, however, the shares of extreme scenarios are opposite to that used in scenario $2.75 \%$ of the characteristics comes from scenario 1 and $25 \%$ from scenario 4 . This means that hydropower production is allocated heavily in the beginning of the load duration curve ( $75 \%$ of the potential to minimize flat rate) and as a result of characteristics of scenario $4 ; 25 \%$ of the profit maximization potential is used. See Figure 5(d) for the description of the hourly hydropower production in this scenario. Here, the peaker demand hours (i.e., hours after the discrete jump in hydro production) are satisfied by using peaker technology.

4.2. Results from Different Hydropower Scenarios. In Table 3 we report the total annual energy consumed, flat rate, and the amounts of different capacities resulting from different hydropower scenarios. The first observation to note is that the flat rate is significantly lower in scenario 1 and somewhat lower in scenario 3 than in the other scenarios. This was of course expected since the target of scenario 1 was to minimize the flat rate by allocating hydropower in the beginning of the load duration curve such that price determining technology is the baseload technology in as many hours as possible. The explanation behind the relatively low flat rate of $53,33 € / \mathrm{MWh}$ in scenario 3 is similar to that of scenario 1 . In scenario 3, however, part of the water reserve is allocated also to peaker hours in order to increase profits. 
TABLE 3: Energy consumed, flat rate, and capacities.

\begin{tabular}{|c|c|c|c|c|c|c|}
\hline Scenario & $\begin{array}{c}\text { Total annual energy } \\
\text { consumed (TWh) }\end{array}$ & Flat rate $€ / \mathrm{MWh}$ & $\begin{array}{c}\text { Hydropower, } \\
\text { MW (max hour) }\end{array}$ & $\begin{array}{c}\text { Midmerit power, } \\
\text { MW (coal and peat) }\end{array}$ & $\begin{array}{c}\text { Peaker power, } \\
\text { MW } \\
\end{array}$ & $\begin{array}{l}\text { Total equilibrium } \\
\text { capacity, } \mathrm{MW}^{15}\end{array}$ \\
\hline Base scenario & 386,62 & 60,76 & 22053 & 10121 & 16576 & 60386 \\
\hline Scenario 1 & 388,43 & 44,27 & 33464 & 0 & 33938 & 79038 \\
\hline Scenario 2 & 386,39 & 61,82 & 32135 & 11634 & 4964 & 60369 \\
\hline Scenario 3 & 387,22 & 53,33 & 32255 & 0 & 16631 & 60522 \\
\hline Scenario 4 & 386,15 & 62,99 & 36479 & 12171 & 63 & 60349 \\
\hline
\end{tabular}

${ }^{15}$ With maximum hourly used hydrocapacity.

TABle 4: Profits, costs, and emissions.

\begin{tabular}{|c|c|c|c|c|c|c|}
\hline Scenario & $\begin{array}{l}\text { Nuclear, profits in } \\
\text { million } €\end{array}$ & $\begin{array}{l}\text { Hydro, profits in } \\
\text { million } €\end{array}$ & $\begin{array}{l}\text { Total costs, } \\
\text { million } €\end{array}$ & $\begin{array}{l}\text { Total costs } \\
€ / \mathrm{MWh}\end{array}$ & $\begin{array}{c}\text { Total emissions } \\
\text { million } \mathrm{tCO}_{2}\end{array}$ & $\begin{array}{l}\text { Emissions } \\
\mathrm{tCO}_{2} / \mathrm{MWh}\end{array}$ \\
\hline Base scenario & 2941,6 & 7082,9 & 13380 & 34,61 & 30,82 & 0,080 \\
\hline Scenario 1 & 1080,2 & 2093,5 & 13941 & 35,89 & 26,41 & 0,068 \\
\hline Scenario 2 & 3087,2 & 7806,5 & 12912 & 33,42 & 31,72 & 0,082 \\
\hline Scenario 3 & 2029,1 & 5369,8 & 13173 & 34,02 & 26,07 & 0,067 \\
\hline Scenario 4 & 3259,0 & 8375,4 & 12613 & 32,66 & 32,88 & 0,085 \\
\hline
\end{tabular}

Another striking thing is that the amount of total equilibrium capacity is clearly higher under scenario 1 than under other scenarios. The reason can be seen from Figure 5(b). Because we use a lot of hydropower from the beginning there will be very large discrete downward jump in the hydro production and after that there is a high need for new installed capacity to satisfy the demand in peaker hours. We can thus say that on the one hand we have a relative low flat rate but at the cost of high amount of total capacity.

In scenario 4 hydropower production is allocated so that peak load technology is the market clearing technology in as many hours as possible. At the same time hydropower production is allocated more to those hours when the wholesale price is at a high level. Resulting from this allocation of hydropower on peak hours we need other technologies less.

Notable is the fact that even though the maximum hourly production by hydropower is relatively similar under scenarios 1, 2, and 3 the hour when this maximum production happens is at a different place in the load duration curve. This has clear impacts on the need for other technologies, the market clearing price, and the resulting flat rate.

Because the peak hour price and the amount of hours at peak quantity are very similar across scenarios they are not reported in the tables. Peak demand price is around $6550 € / \mathrm{MWh}$ in all scenarios and the amount of hours at peak quantity is 55 in every scenario. It is understandable that these values are very similar since the peaker technology is the same in every scenario. The capacity amounts (MWs) of course differ between scenarios.

In Table 4 we report the profits of hydropower and nuclear power producers, production costs, and information on resulting emissions of the different scenarios. In Table 4 we see that the production profiles of hydropower producers also have impacts on the total emissions. It is notable that there seems to be no superior scenario under which we achieve all socially desirable goals. There is a clear tradeoff between allowing high windfall profits to the hydropower and nuclear power producers and the highest cost efficiency. The minimum production costs per MWh are achieved under scenario 4 but it also produces the highest windfall profits to the hydro and nuclear producers. Scenario 4 also results in the highest $\mathrm{CO}_{2}$ emissions per produced MWh.

Scenarios 1 and 3 produce the lowest emissions but these scenarios are not as cost efficient as scenarios which produce higher emissions. Even though it is true that none of the analyzed scenarios is globally superior some policy related conclusions can be drawn. Assuming that low emissions and low windfall profits are politically high priority targets, scenarios 1 and 3 fulfill these targets more efficiently than scenarios 2 and 4 . Consequently, preventing market power to increase windfall profits, society at the same time benefits from lower emissions. However, the total costs of production are higher in otherwise socially desirable scenarios 1 and 3.

\section{Conclusions}

The role of energy is becoming more and more important to households, industries, and society as a whole. The importance of efficiently operating electricity markets with proper environmental targets is increasing. The target of society is to simultaneously reduce emissions and produce electricity cost efficiently. It is important that the long run capacity structure of electricity markets is such that these targets can be reached. In such markets where hydropower is in a significant role the production profile of hydropower affects significantly the efficient amount of other technologies, equilibrium prices of the power market, and the emissions.

In this paper we utilize the real-time pricing simulation model [6-8] in order to study the impact of different hydropower production profiles on the price, capacity structure, windfall profits, and emissions in the Nordic power market. We contribute to the earlier literature in three ways. 
Firstly, we combine hydropower production profiles to the real-time price based simulation model to construct other (other than hydro) technologies. Because real-time metering and pricing of electricity is becoming a real option it is important to use a model which includes this property. The second contribution is relating hydropower production profiles to emissions. Thirdly, we show the impacts of hydropower production profiles on nuclear and hydropower producers' windfall profits.

The main results connected to the prices are that flat rate is significantly smaller in those scenarios where more hydro is allocated to the low-load hours of demand. The explanation is that there will be a significant amount of hours where the wholesale price is driven by baseload technology. However, in the scenario where the flat rate is lowest the total production capacity is highest which raises the question of inefficient investment structure. The reason for this comes from the high utilization of hydropower in the low-load hours which leaves relatively low water reservoirs to be used in peaker load hours. In order to satisfy demand of these hours new peaker capacity has to be built.

There is also a clear difference in the amounts of midmerit and peaker technologies in different scenarios. This is because even though the maximum hourly production by hydropower is relatively similar under scenarios 1,2 , and 3 the hour when this maximum production happens is at a different place in the load duration curve. This has a clear impact on the need for other technologies as well to the market clearing price and consequently to the flat rate.

Our main result connected to the windfall profits, cost efficiency, and emissions is that there seems to be no superior hydropower production profile scenario under which we achieve all socially desirable goals. There is a clear tradeoff between allowing high windfall profits to the hydropower and nuclear power producers with resulting highest cost efficiency. Minimum production costs per MWh are achieved under the scenario which produces highest windfall profits to the hydro and nuclear producer. This scenario also results in the highest $\mathrm{CO}_{2}$ emissions per produced MWh. The scenario which results in the lowest flat rates also results in the lowest emissions. These scenarios are not, however, as cost efficient as scenarios which produce higher emissions. Assuming high societal priority for low emissions and low windfall profits these can be simultaneously reached by allocating hydropower production to the beginning of the load duration curve. The resulting high costs of the system can be reduced by introducing real-time pricing.

\section{Conflict of Interests}

The authors declare that there is no conflict of interests regarding the publication of this paper.

\section{Acknowledgment}

Funding from Yrjö Jahnsson foundation is gratefully acknowledged.

\section{References}

[1] E. S. Amundsen and L. Bergman, "Will cross-ownership reestablish market power in the Nordic power market?" Energy Journal, vol. 23, no. 2, pp. 73-96, 2002.

[2] E. S. Amundsen and L. Bergman, "Why has the Nordic electricity market worked so well?" Utilities Policy, vol. 14, no. 3, pp. 148-157, 2006.

[3] B. Andersson and L. Bergman, "Market structure and the price of electricity: an ex ante analysis of the deregulated Swedish electricity market," Energy Journal, vol. 16, no. 2, pp. 97-109, 1995.

[4] S. Borenstein and J. Bushnell, "An empirical analysis of the potential for market power in California's electricity industry," Journal of Industrial Economics, vol. 47, no. 3, pp. 285-323, 1999.

[5] M. Sandsmark and B. Tennbakk, "Ex post monitoring of market power in hydro dominated electricity markets," Energy Policy, vol. 38, no. 3, pp. 1500-1509, 2010.

[6] S. Borenstein, "The long-run efficiency of real-time electricity pricing," Energy Journal, vol. 26, pp. 1-24, 2005.

[7] S. Borenstein and S. Holland, "On the efficiency of competitive electricity markets with time-invariant retail prices," The Rand Journal of Economics, vol. 36, no. 3, pp. 469-493, 2005.

[8] M. Kopsakangas-Savolainen and R. Svento, "Real-time pricing in the nordic power markets," Energy Economics, vol. 34, pp. 1131-1142, 2012.

[9] J. Bushnell, "A mixed complementarity model of hydrothermal electricity competition in the Western United States," Operations Research, vol. 51, no. 1, pp. 80-93, 2003.

[10] C. Crampes and M. Moreaux, "Water resource and power generation," International Journal of Industrial Organization, vol. 19, no. 6, pp. 975-997, 2001.

[11] T. A. Johnsen, "Hydropower generation and storage, transmission contraints and market power," Utilities Policy, vol. 10, no. 2, pp. 63-73, 2001.

[12] P. Vegard Hansen, "Inflow uncertainty in hydropower markets," Scandinavian Journal of Economics, vol. 111, no. 1, pp. 189-207, 2009.

[13] F. R. Førsund, Hydropower Economics, Springer, New York, NY, USA, 2007.

[14] O. Kauppi and M. Liski, "En empirical model of imperfect dynamic competition and application to hydroelectricity storage," Discussion Paper 232, Helsinki Center of Economic Research, 2008.

[15] M. K. Chang, J. D. Eichman, F. Mueller, and S. Samuelson, "Buffering intermittent renewable power with hydroelectric generation: a case study in California," Applied Energy, vol. 112, pp. 1-11, 2013.

[16] J. K. Kaldellis and K. A. Kavadias, "Optimal wind-hydro solution for Aegean Sea islands' electricity-demand fulfilment," Applied Energy, vol. 70, no. 4, pp. 333-354, 2001.

[17] J. J. Kaldellis, M. Kapsali, and K. A. Kavadias, "Energy balance analysis of wind-based pumped hydro storage systems in remote island electrical networks," Applied Energy, vol. 99, pp. 430-444, 2012.

[18] G. C. Bakos, "Feasibility study of a hybrid wind/hydro powersystem for low-cost electricity production," Applied Energy, vol. 72, no. 3-4, pp. 599-608, 2002.

[19] M. Kapsali, J. S. Anagnostopoulos, and J. K. Kaldellis, "Wind powered pumped-hydro storage systems for remote islands: a complete sensitivity analysis based on economic perspectives," Applied Energy, vol. 99, pp. 430-444, 2012. 
[20] Eurelectric, Power statistics, 2012, http://www.eurelectric.org/ PowerStats2010/.

[21] M. Kopsakangas-Savolainen and R. Svento, "Economic value approach to intermittent power generation in the nordic power markets," Energy and Environment Research, vol. 3, pp. 139-155, 2013.

[22] M. Kopsakangas-Savolainen and R. Svento, Modern Energy Markets, Springer, London, UK, 2012.

[23] T. A. Johnsen, "Demand, generation and price in the Norwegian market for electric power," Energy Economics, vol. 23, no. 3, pp. 227-251, 2001.

[24] N. Damsgaard, Deregulation and regulation of electricity markets [Ph.D. thesis], Stockholm School of Economics, Stockholm, Sweden, 2003.

[25] T. Bye and P. V. Hansen, "How do spot prices affect aggregate electricity demand?” Discussion Paper 527, Research Department of Statistics Norway, 2008.

[26] R. Tarjanne and A. Kivistö, "Comparison of electricity generation costs," Research Report EN A-56, Department of Energy and Environmental Technology, Faculty of Technology, Lappeenranta University of Technology, Lappeenranta, Finland, 2008.

[27] M. Bunn and O. Heinonen, "Preventing the next fukushima," Science, vol. 333, no. 6049, pp. 1580-1581, 2011. 


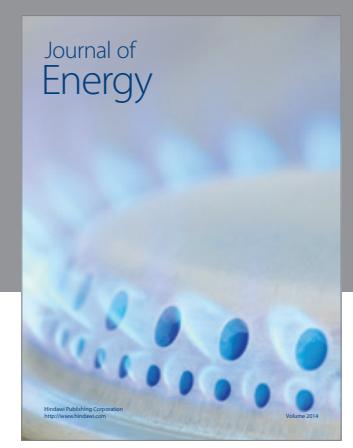

Journal of

Industrial Engineering
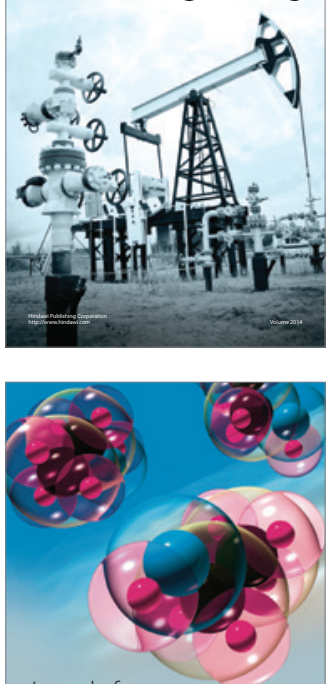

Fuels
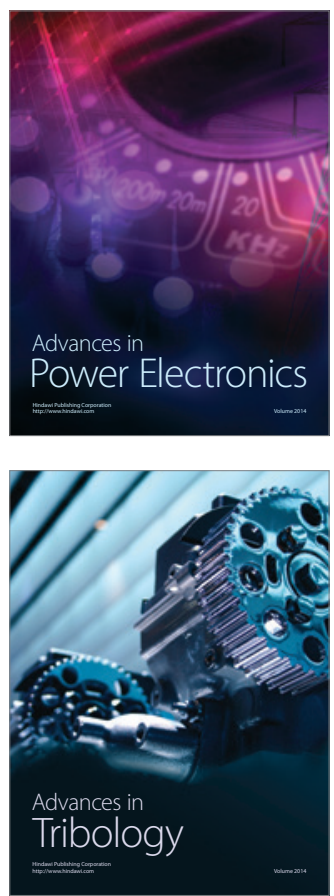

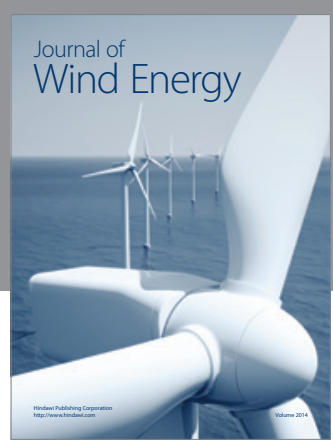

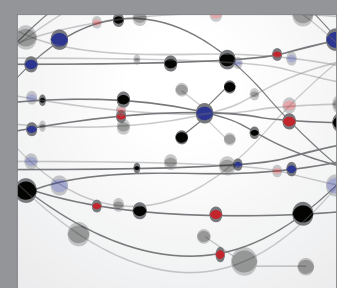

The Scientific World Journal

Submit your manuscripts at http://www.hindawi.com

Journal of

Structures
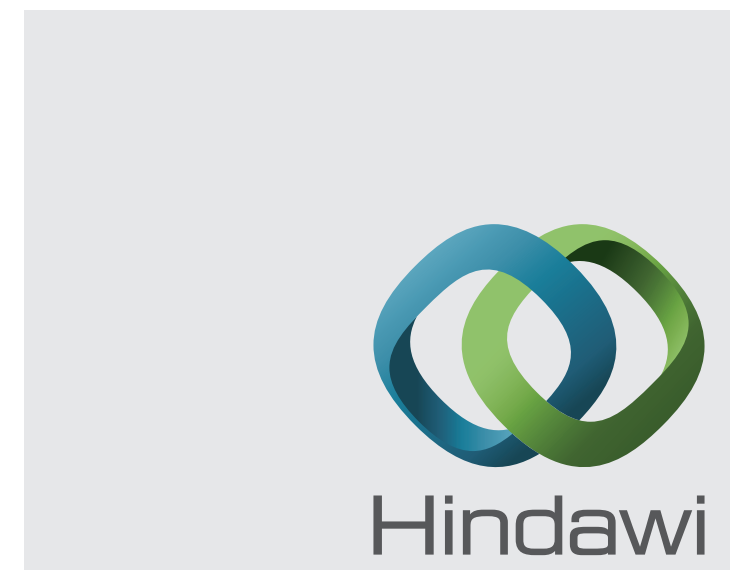

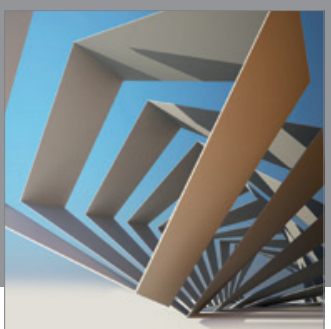

Rotating

Machinery
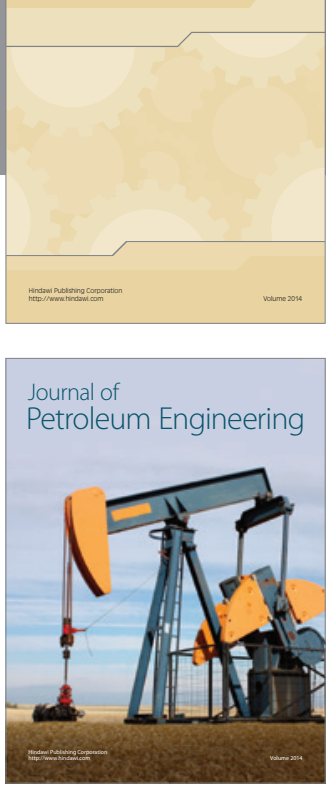

Journal of

Solar Energy
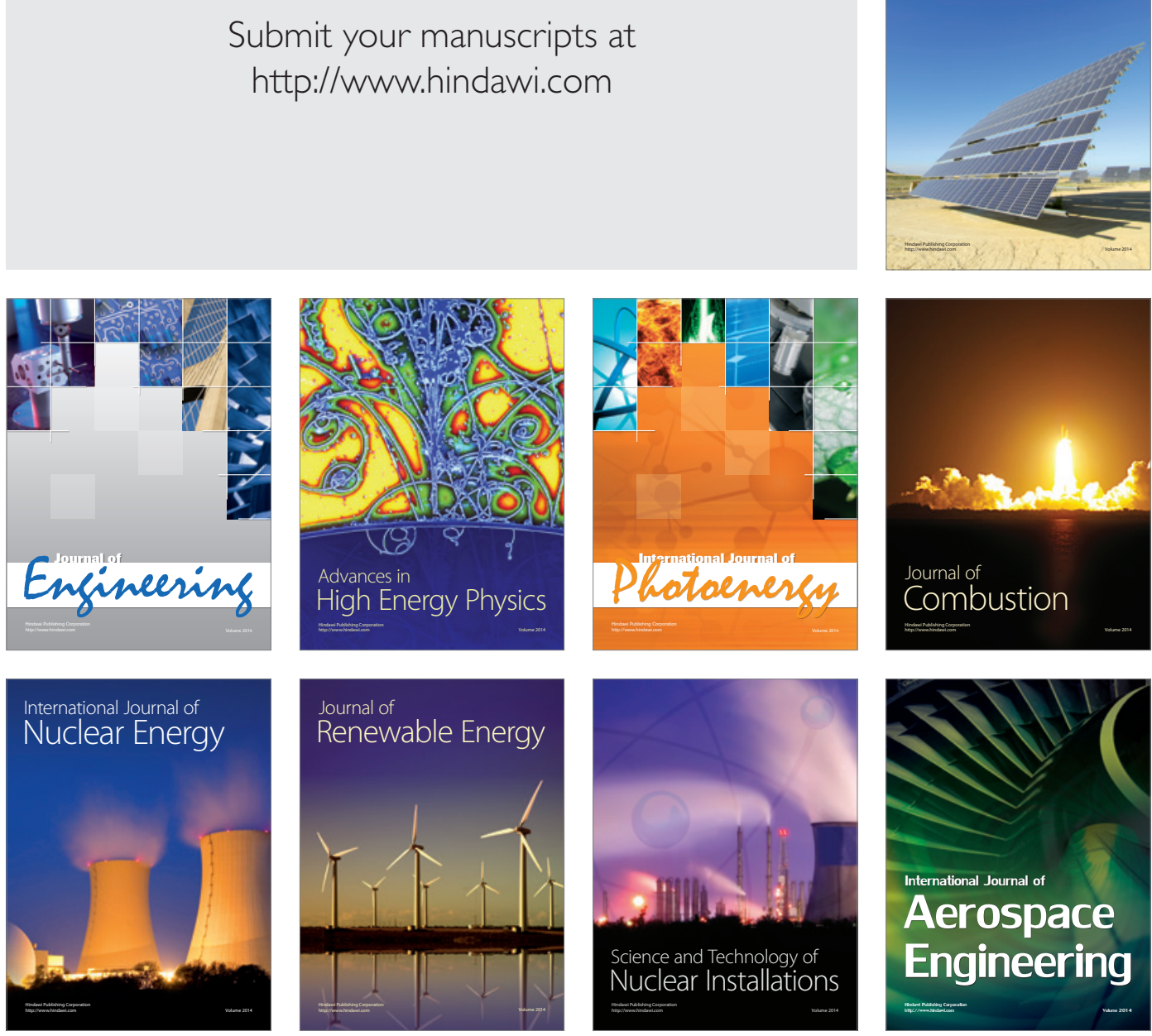